\title{
Colorectal Cancer in Egypt: Clinical, Life-Style, and Socio-Demographic Risk Factors
}

\author{
Ahmed M Hassan, ${ }^{1, *}$ MD, Adel Mohamed Khalaf, ${ }^{1}$ MD, Abd Al-Kareem Elias, ${ }^{1}$ MD.
}

\section{* Corresponding Author: \\ Ahmed M Hassan}

ahmedmohamedhassanahmed.44@azhar.edu.eg

\section{Received for publication June 17, 2021; Accepted September 7, 2021; $\quad$ Published online

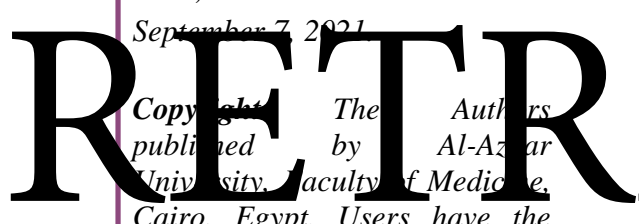 \\ Cairo, Egypt. Users have the right to read, download, copy, distribute, print, search, or link to the full texts of articles under the following conditions: Creative Commons Attribution- Share Alike 4.0 International Public License (CC BY-SA 4.0). \\ doi: $10.21608 /$ aimj.2021.79043.1490 \\ ${ }^{1}$ General Surgery Department, Faculty of Medicine, Al-Azhar \\ University.}

\section{INTRODUCTION}

CRC is a type of cancer that affects the colon and rectum. The mucosa of the colon, rectum, or both are the commonest site of origin.

CRC affects people of all races and ethnicities. It is the third most often recognized cancer in the world, behind lung and breast cancer. In developed regions

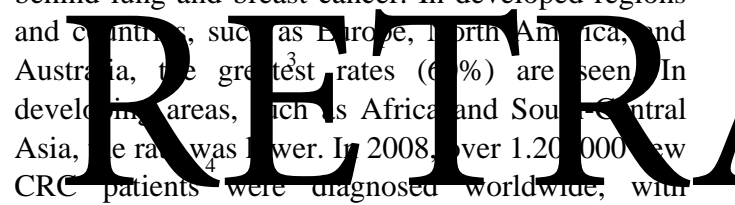

608,700 deaths, so that it is the 4 th most reported reason for cancer death, reporting about $8.0 \%$ of all cancer deaths (1). In the United States, CRC is the 4th more reported cancer.

In Egypt, the estimated rate of CRC is $6.5 \%$ of all malignant tumors, CRC became the sixth most commonly recorded tumor in the years 2002-2003, regarding the National Cancer Institute registry at Cairo University. ${ }^{5}$ It was $4.2 \%$ in men and $3.8 \%$ in females. ${ }^{6}$ CRC is also widespread in Egypt, with 14.0 $\%$ of all colonoscopies revealing the presence of the disease. $^{7}$

\begin{abstract}
Background: Colorectal cancer (CRC) is cancer of the colon and rectum. It arises from the mucosa that lining the colon, rectum or both. mographic risk factors of colorectal cancer in Egypt

Patients and Methodce A hosnital-brsed case-control_studv design was in tis tudy. (n endoscopic, ra ologica ind athol rical me ods and cli xam tions had been $\mathrm{ne}$ for th collection $\mathrm{f}$ data. precancerous colonic lesions, no NSAIDs use, no HRT use, 91, 5.46, 3.69, 6.3, 3.84, and 8.88; respectively).

Conclusion: The most important risk factors of CRC were obesity, DM, IBD, precancerous colonic lesions, and family history of CRC. Risk
\end{abstract} Keywords: Colorectal Cancer; Life-Style; Clinical; Socio-

Disclosure: The authors have no financial interest to declare in relation to the content of this article. The Article Processing Charge was paid for by the authors.

uthorship: All authors have a substantial contribution to the article. 